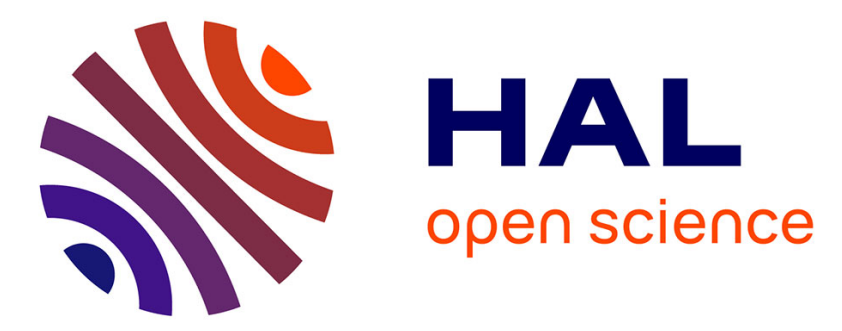

\title{
New Infrastructure Technology and Smart Institutional Interventions: The Case of Implementing Government Cloud Computing in Oman
}

Khalid Alzadjali, Amany Elbanna

\section{To cite this version:}

Khalid Alzadjali, Amany Elbanna. New Infrastructure Technology and Smart Institutional Interventions: The Case of Implementing Government Cloud Computing in Oman. International Working Conference on Transfer and Diffusion of IT (TDIT), Jun 2018, Portsmouth, United Kingdom. pp.126142, 10.1007/978-3-030-04315-5_10. hal-02068941

HAL Id: hal-02068941

https://hal.inria.fr/hal-02068941

Submitted on 15 Mar 2019

HAL is a multi-disciplinary open access archive for the deposit and dissemination of scientific research documents, whether they are published or not. The documents may come from teaching and research institutions in France or abroad, or from public or private research centers.
L'archive ouverte pluridisciplinaire HAL, est destinée au dépôt et à la diffusion de documents scientifiques de niveau recherche, publiés ou non, émanant des établissements d'enseignement et de recherche français ou étrangers, des laboratoires publics ou privés.

\section{(c)(1)}

Distributed under a Creative Commons Attribution| 4.0 International License 


\title{
New infrastructure technology and smart institutional interventions: The case of implementing Government Cloud Computing in Oman
}

\author{
Alzadjali, Khalid ${ }^{1}$ and Elbanna, Amany ${ }^{2}$ \\ ${ }^{1}$ School of Management, Royal Holloway University of London, Egham, Surrey, TE200EX UK, \\ Muscat Municipality, P.O.Box 79, PC 100, Muscat, Sultanate of Oman \\ khalid.alzadjali.2013@live.rhul.ac.uk \\ ${ }^{2}$ School of Management, Royal Holloway University of London, Egham, Surrey, TE200EX UK \\ Amany.Elbanna@rhul.ac.uk
}

\begin{abstract}
Cloud computing technology presents a case of centralised technology that requires adherence to standard and planned approach for its adoption and implementation. There is little knowledge on how institutions could influence the successful migration to the cloud considering the challenges of adopting technology infrastructure. This research questions: How do institutions influence the implementation of cloud computing and to what effect? It examines the institutional intervention practices that influence the migration of the IT services of the Ministry of Health to a national government cloud platform in Oman. The study adopts concepts from institutional theory. The findings reveal that isomorphic pressures play an important role in the successful migration to cloud services. It also shows that mimetic pressure plays a propelling role that supports finding and accepting solutions and pushes the migration forward.
\end{abstract}

Keywords: Information Infrastructure, Cloud Computing, Implementation, Institutional Theory, Isomorphic Mechanisms

\section{Introduction}

Cloud Computing (CC) presents one of the growing new infrastructure technology. It refers to the delivery of computing capabilities as a service to organisations to use over the Internet on a utility-like payment model (Armbrust et al. 2010; Mell et al. 2011b; Wang et al. 2016). Cloud Computing provides an alternative hosting of information technology (IT) services outside organisational boundaries and offers standard uniform services for the entire organisation. The adoption of cloud computing services is rising as organisations seek ways to acquire IT services faster, cheaper and with a shorter implementation time (Gratner 2014; Meulen 2017).

Indeed, the organisational spend on cloud computing adoption continues to soar (Wilczek 2018). Interestingly, reports show that governments interest and spend on cloud computing is similar to other industries. For example, Gartner's recent survey shows that companies spend an average of $20.4 \%$ of their IT budgets on cloud while Local governments spend $20.6 \%$ of their IT budgets on cloud, and national governments spend 22\% (Meulen 2017). With this high level of spend, it is important to understand how governments adopt and migrate to the cloud and how different institutional interventions could be devised to improve the chances of success.

Research suggests that cloud computing adoption by organisations disrupts many of our accumulated knowledge on typical systems implementation and infrastructure complexity (Bhat 2013; Choudhary et al. 2013; Wang et al. 2016). The reported successful stories of cloud adoption and migration contrast the accumulated knowledge regarding IS infrastructure implementation (Star et al. 1994); Hanseth and Moneteiro, 1997; Hanseth al 1996; Hanseth \& Lyytinen, 2006). It also goes against the knowledge that IT implementation in government is typically surrounded by complexity and failure (Avgerou 2000; Currie et al. 2007; Iannacci 2010). Research on Cloud Computing is still in its infancy. There is a need to understand the different adoption dimensions of this new technological infrastructure (Tilson et al. 2010b).

This study aims to understand the nature of institutional interventions that could influence government's agencies adoption and migration to the cloud. It aims to answer the question of: How do institutions influence the implementation of cloud computing and to what effect? To answer the research question, the study examines the migration to government cloud computing services in the 
context of Sultanate Oman. The specific type of cloud computing examined is Infrastructure as a Service (IaaS). The study adopts an institutional perspective considering the important role that institutional context and forces play in systems adoption and implementation (Avgerou 2000; Currie and Guah 2007). This perspective offers a macro view of the institutional action and context that has been largely absent from IS infrastructure research (Iannacci 2010). In doing so, this study contributes to IS infrastructure research as much as it contributes to cloud computing research. It provides an indepth understanding of the institutional actions and practices involved in the interventions to encourage the adoption and migration to cloud services.

Following the introduction, the paper proceeds as follows. The second section presents a brief literature review of CC and IS infrastructure implementation in government. The third section presents the theoretical foundation of the research. The fourth section presents the research methods and describes the case study. The fifth section presents an analysis of the case study and the last section provides further discussion and presents the research's conclusion and contribution.

\section{Literature Review}

This section presents a brief literature review of CC, Information Systems implementation in Government, and IS Infrastructure research in government.

\subsection{Cloud Computing}

The National Institute of Standards and Technologies defines cloud computing as "a model for enabling convenient, on-demand network access to a shared pool of configurable computing resources (e.g., networks, servers, storage, applications, and services) that can be rapidly provisioned and released with minimal management effort or service provider interaction" (NIST 2009). There are three types of services offered through CC. These types are Software as a Service (SaaS), Platform as a Service (PaaS) and Infrastructure as a Service (IaaS) (Armbrust 2010; Creeger 2009; Durkee 2010). Software as a Service (SaaS) refers to business systems that are delivered as a service using the Internet (Armbrust 2010). Platform as a Service (PaaS) means that the users have a cloud environment in which they can develop their environment and use software that they have developed (Armbrust 2010). Infrastructure as a Service (IaaS) is the most basic model of CC services, where the client simply leases the infrastructure that is needed for the application or business continuity requirements (Armbrust 2010). Moreover, cloud computing could be categorised according to its ownership to three main types: public, private and hybrid. Certain types of cloud emerge according to the interest of particular groups, for example, community cloud or government cloud.

Studies of CC focused on the technical aspects particularly in the area of grid computing and virtualisation (Güner et al. 2014; Mahmood et al. 2014; Oliveira et al. 2014; Sabi et al. 2016). Studies that considered the organisational and social aspects are either definitional, factor-based or occupied by proofing the concept by identifying its business benefits. Previous research describes the type of services, offerings and the business benefits of the cloud (Buyya et al. 2010; Creeger 2009; Youseff et al. 2008). Studies have investigated the business values of $\mathrm{CC}$ and viewing it from various perspectives. For example, from the vendor's perspective, some studies identified the key players in the cloud business and future cloud strategies (Bhat 2013; Hoberg et al. 2012). Others studies describe the business values from the client's perspective, organisations as well as individuals (Hoberg et al. 2012; Leimeister et al. 2010; Marston et al. 2011). In this regard, specific areas of business have also been studied, such as healthcare (Giniat 2011; Sultan 2014) and CRM implementation (Petkovic 2010). Studies have also investigated the issues of security (Chang et al. 2016; Goode et al. 2015), regulation (Schneider et al. 2014), policies (Armbrust 2010) of cloud computing and the role of government as a policymaker and regulator (Marston et al. 2011). Other studies examined the determinant of CC adoption and produced lists of factors that affect the adoption including relative advantage, complexity, top management support, firm size, competitive pressure among others (Low et al. 2011; Oliveira et al. 2014)

Although this research is valuable in finding different factors that contribute to the success of $\mathrm{CC}$, it misses in-depth views on its adoption and implementation. A recent survey of CC literature highlights the lack of case studies in the area and also the lack of research that goes beyond the adoption decision of CC to examine the implementation and migration issues (Wang et al. 2016). 


\subsection{Technology Infrastructure}

Technology infrastructure; also identified as digital infrastructure and information infrastructure, has been defined as a group of technologies and human elements, networks, systems and process that contribute to the functioning of an information system Tilson et al. (2010b)). Hanseth et al. (2010)) define Information Infrastructure as:"a shared, open (and unbounded), heterogeneous and evolving socio-technical system (which we call installed base) consisting of a set of IT capabilities and their user, operations and design communities".

Technology infrastructure research has been conducted in information systems from the 1990s with the advent and ubiquitous use of the Internet (Ciborra et al. 1998; Hanseth et al. 1997; Hanseth et al. 1996). However, it continues to present a thin strand of research in IS despite the widespread adoption and diffusion of large technological infrastructure. IS field has focused, in general, on IT governance, system development, and in studying IS effects on individuals, groups, organizations, market and limited research on Information Infrastructure (II) have been introduced when compared with overall IS research (Sidorova et al. 2008). Tilson et al. (2010b)) showed that there is a dearth of IS research on technology infrastructure. They reviewed articles published in ISR and MISQ during the past 20 years reveals that only around $2 \%$ of articles have focused on infrastructural issues (Tilson et al. 2010b). Tilson et al. (2010a)) have also highlighted the existence of weak theoretical grounding and understanding of Information Infrastructure as a new form of IT.

Studies of Information Infrastructure tend to focus on how to conceptualize IT infrastructure (Monteiro et al. 2014). These studies have mainly focused on design (Pipek et al. 2009; Star et al. 1996) and standards making (Hanseth et al. 2006; Hanseth et al. 1997). In this regard, studies examined the tension between the local and global contexts in IT infrastructure design (Braa et al. 2007; Ribes et al. 2009; Ure et al. 2009). Research into the process of implementing IT infrastructure had identified many issues that should be considered when contemplating on introducing information infrastructure. For example, tension between standardisation and flexibilities (Hanseth et al. 2006), tension between top-down and button up governance (Constantinides and Barrett 2014), local and global standardization (Silsand and Ellingsen 2014; Star and Ruhleder 1996), paradox of control (Nielsen and Aanestad 2006), paradox of change (Braa et al. 2007), bootstrapping issues (Hanseth and Aanestad 2003), legitimation (Constantinides and Barrett 2014), and interpretation.

IS infrastructure research has been dominated by a micro perspective that focuses on the development of standards and diverse use of IS infrastructure Pipek et al. (2009)). However valuable and insightful, this micro-level perspective on IS infrastructure has largely overlooked the important role played by institutions in the adoption of IS infrastructure and its large-scale projects (Iannacci 2010). It has not considered the nature of institutional interventions and deliberate actions that influence IS infrastructure adoption. This is despite scholars' longstanding calls arguing for the inevitable role of institutions (King et al. 1994) and invitations for IS researchers to incorporate institutional view in their research (Baptista et al. 2010; Currie 2009; Currie et al. 2009).

IS infrastructure research has largely overlooked the new generation of technology such as cloud computing that requires the migration of IT services to a third party and the model of providing it as a service over the Internet. The adoption and migration to cloud services present a new type of infrastructure that demand uniform implementation and use and hence the top-down approach to the implementation. This new IT infrastructure model questions the relevance of many of the valuable research on standard making, bottom-up approach of implementation and tensions of control and flexibility. It invites research to examine the migration issues and the top-down approach of its implementation.

\section{Theoretical Foundation}

This study adopts the concepts of isomorphic mechanisms from institutional theory as a theoretical lens. Institutional theory (Meyer, 1979; Tolbert and Zucker, 1994; Teo et al., 2003; Scott, 2008:37) provides a powerful explanation to account for the role and influence of external institutions on organisations and outcomes (Liang et al. 2007). Institution is defined as 'a social order or pattern that has attained a particular state or property' Jepperson (1991)). Institutional theory argues that change in organisations are driven by an inevitable push towards what is known as homogenisation (DiMaggio et al. 1991). This homogeneity of organisations is known as isomorphism and is argued to be infused by 
the desire for legitimacy and yielding to institutional forces (DiMaggio and Powell, 1983). Isomorphism can be identified as a process that forces one unit in a population to be similar to other units that face the same set of environmental condition (Currie 2012). There are three types of institutional isomorphic forces, coercive, mimetic, and normative.

Coercive isomorphism occurs when organization comply to the "formal and external pressures exerted upon them by other organizations upon which they are dependent, and the cultural expectations in the society within which the organization's function" (DiMaggio and Powell 1983, p. 150). Coercive pressures can be collections of rules, policies, procedures or collective agreements where the behaviour of every member of an institution is affected by the decisions of those who shape the institution's structure (Kondra et al. 2009). In this regard, government regulations, law and policies are examples of coercive pressure.

Mimetic isomorphism presents tendency of organisations to imitate other organisations perceived to be legitimate. Mimetic isomorphism occurs as a result of organisations attending to uncertainty responding to new problems, unclear goals, poorly understood technology or unclear solutions which invite them to search for a viable solution that has been already implemented or tested by others (DiMaggio et al. 1983).

Normative isomorphism occurs as a result of 'the collective struggle of members of an occupation to define the conditions and methods of their work, to control the production of future member professionals, and to establish a cognitive base and legitimisation for their occupational autonomy' (DiMaggio and Powell 1983, p. 152). This normative pressure considers particular types of behaviours that define goals and objectives as legitimate and designate appropriate ways to achieve them (Scott 2001). Normative isomorphism significantly influences social actions by imposing constraints on social behaviours. These behaviours take the form of political signposting what people are routinely expected to do (Scott 2008).

Table 1: Institutional isomorphic pressures

\begin{tabular}{|l|l|}
\hline $\begin{array}{l}\text { Institutional } \\
\text { Pressures }\end{array}$ & Description \\
\hline Coercive & $\begin{array}{l}\text { The result of both formal and informal pressure posed by one } \\
\text { organisation on the other organisation upon which they are } \\
\text { dependent and by cultural expectations in the society within } \\
\text { which organisations function(DiMaggio et al. 1983) }\end{array}$ \\
\hline Normative & $\begin{array}{l}\text { the normal social action that considers particular types of } \\
\text { processes or behaviours as legitimate(Scott 2001) }\end{array}$ \\
\hline Mimetic & $\begin{array}{l}\text { Occur when new organisation technologies are poorly } \\
\text { understood and when goals are not clear, and their environment } \\
\text { creates uncertainty; the organisation then tend to model } \\
\text { themselves on other organisations(DiMaggio et al. 1983) }\end{array}$ \\
\hline
\end{tabular}

Institutional theory has been widely adopted in organisation studies and management literature (Kostova et al. 2008). In Information Systems, the adoption of institutional theory has been advocated (Mignerat et al. 2009). IS studies adopted it to examine government policies and national level adoption of technology (Grimshaw et al. 2006; King et al. 1994), a particular sector, industry (Chiasson et al. 2005) or a single organisation (Davidson et al. 2007; Gosain 2004). The institutional isomorphic pressures has also been used in IS research (Gosain 2004) to examine the adoption of technology such as website (Flanagin 2000), EDI (Teo et al. 2003), ERP (Benders et al. 2006; Liang et al. 2007) and for supply chain (Lai et al. 2006) and outsourcing (Ang et al. 1997), compliance to security behaviour and policies (Herath et al. 2009; Hu et al. 2007).

Previous research on IT infrastructure has paid insufficient attention to the institutional perspective in favour of examining micro-level practices and scholars argue for the importance and value of adopting an institutional lens and considering the role of institutions (Iannacci 2010). Recently, Monteiro et al. (2014)) argue that studying IT Infrastructure from institutional theory perspective "can be a major enhancement to examine what scope exists for proactive Information Infrastructure interventions, policy, and governance-and how these may vary under different Information Infrastructure forms and settings" (Monteiro et al. 2014). 


\section{$4 \quad$ Research Methodology}

\subsection{Research setting}

The case study explores the implementation of the national government cloud computing project in Oman (Oman G-Cloud). Sultanate of Oman is a country located in the Arabian Peninsula bordered by United Arab Emirates, Saudi Arabia, and Yemen. Oman is part of the Gulf Cooperation Council (GCC) which also includes the following countries; Saudi Arabia, UAE, Qatar, Bahrain, and Kuwait (GCC 2015). GCC countries are unique in their stage of development. The United Nations Development Programme in Human Development Index considered GCC countries in 2015 as "very highly ranked" in human development placed right below developed countries and well above other developing countries and Oman is ranked $52^{\text {nd }}$ in this index (UNDP 2015). This unique status of GCC allows them to be studied independently. Also, they share similar cultural, economic, social and political characters which can be different from other developing countries. Moreover, the last United Nation's E-government Survey in 2014 ranked Oman $48^{\text {th }}$ in the E-government development index increasing 18 ranks from the 2010 survey.

Oman G-Cloud is one of the e-government initiatives where the implementation started in 2014. The initiative is intended to provide services to the government agencies in Oman and to set up a shared infrastructure including servers, network, storages and applications to all government agencies to meet all their IT infrastructure requirements. The rationale of the project is that having G-Cloud in place, government agencies can focus on their core business, reducing the IT budget, increasing their agility and providing the public e-Services at higher efficiency (ITA 2015). The project is owned by the Information Technology Authority of Oman (ITA). ITA has proposed to all government agencies a government $\mathrm{CC}$ services to achieve its e-government objectives and integration. ITA decided to implement the private cloud model. The private cloud is a model where the cloud infrastructure is operated exclusively for an organization. This model can be managed by the organization or a third party, and it is can be within the organization premises or outside (Mell et al. 2011a). With this model, the ITA has decided to build G-Cloud using Open Source (OpenStack). Using Open source was a strategic decision to avoid the lock-in challenges of the off-the-shelf package along with many other typical benefits of open source. On December 19, 2013, ITA signed an agreement with Nortal; an international software development company, for the supply, design, delivery, implementation and operation of the G-Cloud for three years. During the time when the data collection was conducted for this research, there were several projects which were hosted through the G-Cloud. One of these projects is the Ministry of Health(MoH) e-portal (MoH e-portal) which is the focus of this paper.

\subsection{Research methods}

This research adopts a qualitative interpretive approach which allows in-depth exploration of social and cultural phenomena (Myers 2010). It views people as social actors capable of creating and interpreting their own independent and inter-dependent meanings as they interact with the world around them (Orlikowski et al. 1991; Saunders et al. 2007). The use of theory in this research paradigm offers an initial framework and sensitising device that help researchers to make sense of the collected data (Gregor 2006; Miles et al. 1994; Walsham 1995). It adopts a case study approach to gain a rich understanding of the phenomenon (Myers 1997; Walsham 1995) in its natural setting (Benbasat et al. 1987; Yin 2014). This approach is well suited to the research questions that require a detailed understanding of institutional influences.

The level of analysis of this research is on the national level as the government CC project in Oman is being implemented for the whole government of the country. Different government agencies are utilizing or are in the process of utilizing the government cloud. The research reported here is part of a wider project to examine the implementation of government cloud in Sultanate of Oman. It focuses on the national project of CC led by the Information Technology Authority of Oman (ITA) and the Ministry of Health adoption. This type of case study is considered as an embedded (Multiple units of analysis) single case (Yin 2014).

Multiple sources of data collection were employed. They include 30 face-to-face interviews with senior managers, managers, technical staff and vendors of Information Technology Authority of Oman (ITA) and the Ministry of Health (MoH). Interviews were conducted in the period between 29/07/2015 and $27 / 12 / 2015$. All interviews were recorded and transcribed verbatim. Interviews lasted between 40 
minutes and two hours with an average of one hour. Interviewees were chosen from management and technical levels on the basis of their involvement in G-cloud. Documents were also reviewed including government reports, vendors' reports and presentation slides, websites in addition to technical manuals and reports. Data collection continued until saturation was reached and no further information was emerging from data sources (Marshall et al. 2013) Fossey et al. (2002) Saunders et al. (2007). The first author has also utilized by invitation only chat groups on WhatsApp (the online chat application) of professionals working on the project. This group discussed IS and government issues freely and anonymously in some cases, which presented an excellent opportunity for the researcher to observe these conversations. It was also an opportunity to ask questions and get feedback from many professionals.

All transcriptions and documents have been carefully read and were subject to open coding. The data were not forced into categories but allowed emerge through creating new categories. For example, coercive and mimetic mechanisms were much prominent in the data than normative mechanisms reflecting that they had a stronger influence in the implementation.

\section{Research findings}

The research findings highlight that the $\mathrm{MoH}$ cloud implementation project has faced different institutional pressures. These pressures have pushed the implementation forward and encouraged $\mathrm{MoH}$ to adopt and migrate to the cloud. The following sections present the different institutional pressures and interventions that influenced the adoption and implementation of cloud computing in the Ministry of Health $(\mathrm{MoH})$.

\subsection{Coercive institutional pressure}

$\mathrm{MoH}$ has been subjected to different practices that exerted coercive pressure on it to adopt the G-cloud. These practices are categorized as political power, centralized policies, financial resources, rules and regulations, compliance and standardizations.

The political power of ITA made it possible for it to give priorities to projects that are consistent with the G-cloud. One of the senior managers at the ITA explains:

'we are giving priorities to the e-transformation projects, many of the e-transformation projects are under development or on planning phase, so it makes it easy for the organizations and for ITA to build their application on the G-cloud-enabled environment from the start'.

In addition, ITA is mandated by the cabinet's office to achieve e-government, which granted further power to ITA over government agencies and ministries where $\mathrm{MoH}$ is one.

In addition, the ITA senior executives had a good relationship with the MoH senior managers, which helped the implementation of G-Cloud. One of the IT management team in MoH states that:

'The decision was made by a senior manager in Ministry of Health and a senior manager in ITA to join the G-Cloud and the G-cloud team in ITA, and the member of the evaluation team in e-tender have evaluated which company who will do the implementation of e-health portal along with hosting it in the G-Cloud'.

The political power of ITA together with the established relationship with senior management of $\mathrm{MoH}$ has influenced the decision of $\mathrm{MoH}$ to join and influenced $\mathrm{MoH}$ staff to accept this decision.

The financial incentives that ITA offered have also played an important role in making $\mathrm{MoH}$ migration to the G-cloud favourable. Staff agree that the zero charge policy that ITA offered was an incentive to join the cloud. While ITA has offered $\mathrm{MoH}$ to the join the G-cloud amidst the latter involvement in tendering and contractual arrangement with the supplier of the e-health portal, the financial incentives ITA offered made joining the G-cloud a cheaper option that gave it the necessary incentive to change its contractual and tendering arrangement. A senior IT manager in the MoH stated:

'Well after we had distributed the tender of e-Health project, the G-Cloud was not in the picture at all. After that, we knew that the ITA started to build the G-Cloud. We again asked 
the vendors to provide us with the financial cost if we move to G-Cloud and how much will it cost us. We found out that the G-Cloud is much better financially' MOH01, 29/07/2015.

Another MoH IT manager also added that:

'Joining the G-Cloud was mainly to save cost on the hardware. It was the time we were finalising the tender, and then the ITA was offering this solution, and it was offered for free' MOH02, 29/07/2015.

However, financial resources were not the only leverage suited to apply pressure into joining the G-Cloud. Human resources that were provided as Management Control with the G-Cloud were also another important factor in influencing how the e-Health portal would be implemented in the G-Cloud. Accepting to join the G-Cloud meant that the $\mathrm{MoH}$ information infrastructure would be managed and controlled by a professional government agency that had the human resources capable of managing different information infrastructure areas such as network and security. One of the ITA's Project managers clarified this by saying:

'If I am in the G-Cloud, I am free of my responsibility... It will be the responsibility of the GCloud team to set the G-Cloud environment to set up for the ministry; then the vendor was given access. So for me, as a Ministry, I do not have to worry about it. The second scenario, which is hosting in the Ministry. I have to deploy a Ministry IT team, which I think does not have the capabilities to do that. So, we are freeing the MOH from HR requirements also' ITA07, 30/11/2015.

During the implementation of the e-Health project, the standards set by the ITA for all government agencies to join the G-Cloud faced challenges. These standards could be considered the rules and regulations to which any government agencies that wanted to join the G-Cloud would have to comply. The e-Health project was the first one for the G-Cloud to host an application from an external government agency. As such, it was a learning curve for both the ITA and MoH teams, as they faced many new and unexpected challenges. From the early implementation period, the e-Health's vendor used an agile methodology approach. This meant that some e-Health modules could be activated as soon as they were completed, with no need to wait for the whole portal to be ready. The e-Health team's requirements pressured the G-Cloud team to have the G-Cloud ready for the e-Health portal which has resulted in a temporary stage solution. A vendor staff member stated:

'To achieve our requirement; the ITA came up with the concept called the mini-cloud. So, while the ITA was doing the proper cloud project on the side, they did a mini-cloud for the $\mathrm{MoH}$ to cater for our requirement' MOH08, 23/08/2015.

As the implementation stages progressed, the ITA team started introducing more standards to be applied to the e-Health portal. Some of these had been clearly communicated to the MoH team through different means — such as documents — while others, such as security standards, were introduced later.

Moreover, the $\mathrm{MoH}$ was the first who implemented several security standards. The ITA's project manager for the $\mathrm{MoH}$ added:

'All the policies that were prescribed by the ITA were put there. It was first as to have everything to be as per Public Key Infrastructure (PKI), and Mobile PKI for users who wanted to get access the username and password. We were the first who implemented the integration with MOC (Ministry of Commerce) and integration with ROP (Royal Oman Police) for all the G-to-B services through the ITA integration platform. We were also the first who used the cyber sources e-payment and so many things we used to do for the first time' ITA07, 30/11/2015.

Although some of these standards, such as the PKI, were hard to implement, the MoH agreed to them because of top-down pressure from the ITA, and because it believed it would benefit from them in the long run.

Moreover, the MoH had to comply with the ITA's rules and regulations when it came to where to host its application. Another IT manager of the MoH explained: 
'I think there are instructions from the ITA that any portal has to be hosted inside Oman, not outside the country. It has to be hosted in the G-Cloud, or it must be hosted internally. I consider it to be dangerous if it is not hosted internally inside Oman. I cannot imagine seeing my data to be managed or hosted by a cloud company outside Oman or by a private corporation. So it is fine as it is now, hosted by the ITA G-Cloud, as they have secured MPLS' MOH04, 09/08/2015.

\subsection{Normative institutional pressure}

Normative institutional force also influenced the implementation of standards for the e-Health portal in the G-Cloud. One of these stemmed from ITA building general knowledge base for $\mathrm{MoH}$ team of the team who managed and implemented the e-Health portal. One of the MoH's IT managers stated:

'I know the G-Cloud can provide you with high availability and can have an endless amount of space' MOH02, 29/07/2015. 'The ITA held several seminars, and they invited us. We understand it, and we encourage it' MOH05, 11/08/2015.

During the implementation, the normative pressure derived from the MoH's team resulted in contesting some standards introduced by the ITA. The MoH staff and vendor's general knowledge enabled them to contest the implementation process, request a Mini-cloud, and overcome some security standard issues in the initial stages of the implementation. Departments such as networking and security had their concerns over the G-Cloud's implementation and had requested to ease the way of verifying requests. The $\mathrm{MoH}$ is a large government agency with over 240 sites all over Oman, and many of its IT staff members held the privileges needed to make changes to their application. Once the e-Health portal was hosted in the G-Cloud, making local changes was no longer possible. One of the MoH's managers stated that:

'The ITA wanted to impose their standards on our system, especially the security standards. For example, they had many concerns, and we asked them to give us many exceptions.. almost every action we took, nearly every click returned an error from the ITA, because they had to analyse all the traffic to make sure it was not an attack, so they had to make an exception on their system to make it pass' MOH02, 29/07/2015.

A project specialist also raised his concerns for the usability of the PKI system, which is an embedded standard throughout the G-Cloud in the MoH portal, by saying:

'We understand this has to be a hard effort and it might affect the usability of the portal, but then we had a long discussion, me and the DG of IT, so we thought about it, and we preferred to start from the beginning and mitigate that risk as a PKI team' ITA07, 30/11/2015.

\subsection{Mimetic institutional pressure}

Mimetic practices played a major part in the implementation of the e-health. Participants were convinced that the implementation of this standard infrastructure, however, might not suit their immediate needs, cannot be escaped as they perceived it as presenting an international standard that other countries and organisations adopt. They believed that since others implemented it, then they had to implement it as well. This view has surfaced in most interviews. For example, one of the managers of the e-health portal describes the G-cloud as "a new trend in hosting government network". The ehealth portal management also adds:

'If you look at other countries experience you will find that they have one portal for the whole government and G-Cloud would help in this one portal" and the network manager adds "I believe the whole world is going to the cloud". Staff believed that "it is the latest trend and that "the whole world is going to the cloud' MOH04, 09/08/2015. They looked at other countries that had implemented cloud computing and considered this to be a legitimate reason to be part of the G-Cloud. The e-Health portal management team elaborated on that by saying: 'If you look at other countries' experience, you will find that they have one portal for the whole government, and the G-Cloud would help in this one portal' MOH03, 09/08/2015. 
The view that it has been successfully implemented by other countries such as Estonia has played an important role in pushing the implementation forward and overcoming disagreements and issues raised.

\section{Discussion}

This research questioned: How do institutions influence the implementation of cloud computing and to what effect? It examined the case of national government $\mathrm{CC}$ in Oman and in particular the implementation case of Ministry of Health e-Health portal. The research findings showed institutional pressures play an important role in information infrastructure solutions such as the G-Cloud. The GCloud is a form of information infrastructure in which resources are centralised and work in the virtual setting. Applying standardisation to the different government agencies became one of the leading challenges of implementing the G-Cloud. It is argued in this research that coercive, mimetic, and normative institutional forces play an important role in implementing the G-Cloud.

The study shows that the coercive and mimetic forces play a significant role in establishing the standards which allowed successful implementation of the G-Cloud in $\mathrm{MoH}$. The normative pressures led professionals to resist some of the standards of G-Cloud. However, propelled by the mimetic pressure, these professional were fast in finding solutions and compromises. This was particularly exhibited in the finding of temporary stage solution of the mini-cloud to overcome the existence of different requirements and timetables.

The finding differs from Currie (2012)) work where institutional isomorphic forces became conflicted with efforts to impose organizational change. While IT professionals in MoH negotiated the standards, which were enforced from the G-cloud team over the e-health portal, this has not resulted in resistance and implementation failures as the National Health program in Currie (2012)) study. The zero-charge policy was a motive to join the G-Cloud alongside other financial incentives. The research shows that $\mathrm{MoH}$ was encouraged to adopt $\mathrm{CC}$ as a way of solving the complexities and saving cost when implementing large Information Infrastructure in a government organization. This was further enforced by the mimetic pressure of CC as a new trend that has been successfully implemented in other countries and large organisations. These findings contrast what previous research emphasised regarding the negative results of negotiation, contesting and resistance of standards implementations in infrastructure adoption (Hanseth et al. 2010; Sahay et al. 2009). Evidence of the problems and failures of centralized control in public sector infrastructure development from top-down are clear in the literature (Adler-Milstein et al. 2008; Currie et al. 2007). The case study shows that the G-cloud implementation that comes with standards from a national government can be achieved. This contrasting finding could be due to the nature of the cloud computing as a centralised technology that requires standard approach to the migration.

\section{Conclusion}

While technology infrastructure research has maintained a micro organisational focus and has not paid attention to the possibility of intervention, this study shows that successful CC implementation requires institutional intervention. This responds to Monteiro et al. (2014)) call for research on IT Infrastructure "to examine what scope exists for proactive Information Infrastructure interventions".

This paper makes several contributions to the IS field in general and, more specifically, to the study of information infrastructure, cloud computing, and institutional theory in IS. The paper contributes to existing theory in the area of information infrastructure by investigating the implementation of cloud computing through the lens of institutional theory. There are few previous studies of information infrastructure implementation at the macro level (Brown et al. 2011; Hanseth et al. 1998; Iannacci 2010). Adopting the institutional perspective is important in view of the role that institutional forces play in information infrastructure implementation (Avgerou 2000; Currie et al. 2007). Moreover, this paper contributes to the area of cloud computing by investigating the adoption and implementation of cloud computing in government. It describes qualitative, interpretive, and empirical research into cloud computing, an area in which there is a dearth of previous research. The study contributes to institutional theory in IS by providing a comprehensive understanding of how various institutional forces impact information infrastructure. It identifies three institutional forces that play different roles in the implementation process. 
The findings of this paper and their implications also make important contributions to practice. Although government organisations and particularly health sector have previously invested in IT infrastructure projects, many of these failed to achieve their objectives or were only delivered after long delays. This study provides government decision makers with useful insights into how institutional forces can help to achieve the implementation of new forms of information infrastructure solutions, such as cloud computing.

This paper lays the ground for several future studies. It focused only on the IaaS type of cloud computing. Future research could explore other types of services, such as PaaS and SaaS, and explore government agencies' implementation issues using these services. Future research could also study the effect of the institutional forces on cloud computing implementation in developed countries. Another and possibly related area that needs study is the influence of national culture on the acceptance of information infrastructure standards. 


\section{References}

1. Adler-Milstein, J., McAfee, A. P., Bates, D. W., and Jha, A. K. 2008. "The state of regional health information organizations: current activities and financing," Health Affairs (27:1), pp 60-69.

2. Ang, S., and Cummings, L. L. 1997. "Strategic response to institutional influences on information systems outsourcing," Organization science (8:3), pp 235-256.

3. Armbrust, M., Fox, A., Griffith, R., Joseph, A. D., Katz, R., Konwinski, A., Lee, G., Patterson, D., Rabkin, A., and Stoica, I. 2010. "A view of cloud computing," Communications of the ACM (53:4), pp 50-58.

4. Armbrust, M., Fox, A., Griffith, R., Joseph, A. D., Katz, R., Konwinski, A., ... \& Zaharia, M. 2010. "A view of cloud computing " Communications of the ACM (53:4), pp 50-58.

5. Avgerou, C. 2000. "IT and organizational change: an institutionalist perspective," Information Technology \& People (13:4), pp 234-262.

6. Baptista, J., Newell, S., and Currie, W. 2010. "Paradoxical effects of institutionalisation on the strategic awareness of technology in organisations," The Journal of Strategic Information Systems (19:3), pp 171-183.

7. Benbasat, I., Goldstein, D. K., and Mead, M. 1987. "The case research strategy in studies of information systems," MIS quarterly (11:3), pp 369-386.

8. Benders, J., Batenburg, R., and Van der Blonk, H. 2006. "Sticking to standards; technical and other isomorphic pressures in deploying ERP-systems," Information \& Management (43:2), pp 194-203.

9. Bhat, J. M. 2013. "Adoption of Cloud Computing by SMEs in India: A study of the Institutional Factors," Proceedings of the Nineteenth Americas Conference on Information Systems).

10. Braa, J., Hanseth, O., Heywood, A., Mohammed, W., and Shaw, V. 2007. "Developing health information systems in developing countries: the flexible standards strategy," Mis Quarterly (31:2), pp 381-402.

11. Brown, D. H., and Thompson, S. 2011. "Priorities, policies and practice of e-government in a developing country context: ICT infrastructure and diffusion in Jamaica," European Journal of Information Systems (20:3), pp 329-342.

12. Buyya, R., Broberg, J., and Goscinski, A. M. 2010. Cloud Computing: Principles and Paradigms, ( John Wiley \& Sons: New York.

13. Chang, V., and Ramachandran, M. 2016. "Towards achieving data security with the cloud computing adoption framework," IEEE Transactions on Services Computing (9:1), pp 138-151.

14. Chiasson, M. W., and Davidson, E. 2005. "Taking industry seriously in information systems research," Mis Quarterly), pp 591-605.

15. Choudhary, V., and Vithayathil, J. 2013. "The Impact of Cloud Computing: Should the IT Department Be Organized as a Cost Center or a Profit Center?," Journal of Management Information Systems (30:2), pp 67100.

16. Ciborra, C. U., and Hanseth, O. 1998. "From tool to to Gestell: Agendas for managing the information infrastructure," Information Technology \& People (11:4), pp 305-327.

17. Creeger, M. 2009. "Cloud Computing: An Overview," ACM Queue (7:5), pp 626-631.

18. Currie, W. 2009. "Contextualising the IT artefact: towards a wider research agenda for IS using institutional theory," Information Technology \& People (22:1), pp 63-77.

19. Currie, W. L. 2012. "Institutional isomorphism and change: the national programme for IT-10 years on," Journal of Information Technology (27:3), pp 236-248.

20. Currie, W. L., and Guah, M. W. 2007. "Conflicting institutional logics: a national programme for IT in the organisational field of healthcare," Journal of Information Technology (22:3) Sep, pp 235-247.

21. Currie, W. L., and Swanson, E. B. 2009. "Special issue on institutional theory in information systems research: contextualizing the IT artefact," Springer.

22. Davidson, E. J., and Chismar, W. G. 2007. "The interaction of institutionally triggered and technologytriggered social structure change: an investigation of computerized physician order entry," MIS quarterly (31:4), pp 739-758.

23. DiMaggio, P. J., and Powell, W. W. 1983. "The iron cage revisited: Institutional isomorphism and collective rationality in organizational fields," American sociological review), pp 147-160.

24. DiMaggio, P. J., and Powell, W. W. 1991. The new institutionalism in organizational analysis, (Chicago University: Chicago, USA.

25. Durkee, D. 2010. "Why cloud computing will never be free," in ACM Queue, pp. 01-10.

26. Flanagin, A. J. 2000. "Social pressures on organizational website adoption," Human communication research (26:4), pp 618-646.

27. GCC 2015. "Foundations and Objectives of GCC."

28. Giniat, E. J. 2011. "Cloud computing: innovating the business of health care," healthcare financial management (65:5) May, pp 130-131.

29. Goode, S., Lin, C., Tsai, J. C., and Jiang, J. J. 2015. "Rethinking the role of security in client satisfaction with Software-as-a-Service (SaaS) providers," Decision Support Systems (70), pp 73-85.

30. Gosain, S. 2004. "Enterprise information systems as objects and carriers of institutional forces: the new iron cage?," Journal of the Association for Information Systems (5:4), p 6.

31. Gratner 2014. "Predicts 2014: Cloud Computing Affects All Aspects of IT."

32. Gregor, S. 2006. "The nature of theory in information systems," Mis Quarterly (30:3), pp 611-642.

33. Grimshaw, D., and Miozzo, M. 2006. "Institutional effects on the IT outsourcing market: Analysing clients, suppliers and staff transfer in Germany and the UK," Organization studies (27:9), pp 1229-1259. 
34. Güner, E. O., and Sneiders, E. Year. "CLOUD COMPUTING ADOPTION FACTORS IN TURKISH LARGE SCALE ENTERPRISES," PACIS, AISeL, Chendu, China, 2014, pp. 353-361.

35. Hanseth, O., Jacucci, E., Grisot, M., and Aanestad, M. 2006. "Reflexive standardization: Side effects and complexity in standard making," Mis Quarterly (30:Special Issue), pp 563-581.

36. Hanseth, O., and Lyytinen, K. 2010. "Design theory for dynamic complexity in information infrastructures: the case of building internet," Journal of Information Technology (25:1), pp 1-19.

37. Hanseth, O., and Monteiro, E. 1997. "Inscribing behaviour in information infrastructure standards," Accounting, management and information technologies (7:4), pp 183-211.

38. Hanseth, O., and Monteiro, E. Year. "Changing irreversible networks," ECIS, http://www.idi.ntnu.no/ ericm/ecis.html1998, pp. 1123-1139.

39. Hanseth, O., Monteiro, E., and Hatling, M. 1996. "Developing information infrastructure: The tension between standardization and flexibility," Science, technology \& human values (21:4), pp 407-426.

40. Herath, T., and Rao, H. R. 2009. "Encouraging information security behaviors in organizations: Role of penalties, pressures and perceived effectiveness," Decision Support Systems (47:2), pp 154-165.

41. Hoberg, P., Wollersheim, J., and Krcmar, H. Year. "The Business Perspective on Cloud Computing-A Literature Review of Research on Cloud Computing," AMCIS, AISeL2012.

42. Hu, Q., Hart, P., and Cooke, D. 2007. "The role of external and internal influences on information systems security-a neo-institutional perspective," The Journal of Strategic Information Systems (16:2), pp 153-172.

43. Iannacci, F. 2010. "When is an information infrastructure? Investigating the emergence of public sector information infrastructures," European Journal of Information Systems (19:1), pp 35-48.

44. ITA. 2015. "ITA G-Cloud overview," ITA.

45. Jepperson, R. L. 1991. "Institutions, Institutional Effects, and Institutionalism, in W.W. Powell and P. DiMaggio " in The New Institutionalism in Organizational Analysis, University of Chicago Press: Chicago, USA, pp. 143-163.

46. King, J. L., Gurbaxani, V., Kraemer, K. L., McFarlan, F. W., Raman, K., and Yap, C.-S. 1994. "Institutional factors in information technology innovation," Information systems research (5:2), pp 139-169.

47. Kondra, A. Z., and Hurst, D. C. 2009. "Institutional processes of organizational culture," Culture and Organization (15:1), pp 39-58.

48. Kostova, T., Roth, K., and Dacin, M. T. 2008. "Institutional theory in the study of multinational corporations: A critique and new directions," Academy of management review (33:4), pp 994-1006.

49. Lai, K.-h., Wong, C. W., and Cheng, T. E. 2006. "Institutional isomorphism and the adoption of information technology for supply chain management," Computers in Industry (57:1), pp 93-98.

50. Leimeister, S., Böhm, M., Riedl, C., and Krcmar, H. 2010. "The business perspective of cloud computing: Actors, roles and value networks," in ECIS Proceedings, AISeL, pp. 1-12.

51. Liang, H., Saraf, N., Hu, Q., and Xue, Y. 2007. "Assimilation of enterprise systems: the effect of institutional pressures and the mediating role of top management," MIS quarterly), pp 59-87.

52. Low, C., Chen, Y., and Wu, M. 2011. "Understanding the determinants of cloud computing adoption," Industrial management \& data systems (111:7), pp 1006-1023.

53. Mahmood, M. A., Arslan, F., Dandu, J., and Udo, G. 2014. "Impact of Cloud Computing Adoption on Firm Stock Price-An Empirical Research," in AMCIS.

54. Marston, S., Li, Z., Bandyopadhyay, S., Zhang, J., and Ghalsasi, A. 2011. "Cloud computing-The business perspective," Decision Support Systems (51:1), pp 176-189.

55. Mell, P., and Grance, T. 2011a. "The NIST definition of cloud computing (draft)," NIST special publication (800:145), p 7.

56. Mell, P., and Grance, T. 2011b. "The NIST Definition of Cloud Computing: Recommendations of the National Institute of Standards and Technology," The National Institute of Standards and Technology - The US department of Commerce

57. Meulen, R. v. d. 2017. "Understanding Cloud Adoption in Government," in Gartner: https://www.gartner.com/smarterwithgartner/understanding-cloud-adoption-in-government/.

58. Mignerat, M., and Rivard, S. 2009. "Positioning the institutional perspective in information systems research," Journal of Information Technology (24:4), pp 369-391.

59. Miles, M. B., and Huberman, A. M. 1994. Qualitative data analysis : an expanded sourcebook (2nd ed ed.) London, England: California, USA.

60. Monteiro, E., Pollock, N., and Williams, R. 2014. "Innovation in Information Infrastructures: Introduction to the Special Issue," Journal of the Association for Information Systems (15:4), p 4.

61. Myers, M. 2010. "Qualitative Research in Information Systems," Association for Information Systems, Available at: http://www.qual.auckland.ac.nz/).

62. Myers, M. D. 1997. "Qualitative research in information systems," Management Information Systems Quarterly (21:2), pp 241-242.

63. NIST 2009. "Working definition of cloud computing," in US government.

64. Oliveira, T., Thomas, M., and Espadanal, M. 2014. "Assessing the determinants of cloud computing adoption: An analysis of the manufacturing and services sectors," Information \& Management (51:5), pp 497-510.

65. Orlikowski, W. J., and Baroudi, J. J. 1991. "Studying information technology in organizations: Research approaches and assumptions," Information systems research (2:1), pp 1-28.

66. Petkovic, I. Year. "CRM in the cloud," IEEE IEEE, Subotica, Serbia, 2010, pp. 365-370. 
67. Pipek, V., and Wulf, V. 2009. "Infrastructuring: Toward an Integrated Perspective on the Design and Use of Information Technology," Journal of the Association for Information Systems (10:5), pp 447-473.

68. Ribes, D., and Finholt, T. A. 2009. "The Long Now of Technology Infrastructure: Articulating Tensions in Development," Journal of the Association for Information Systems (10:5), pp 375-398.

69. Sabi, H. M., Uzoka, F.-M. E., Langmia, K., and Njeh, F. N. 2016. "Conceptualizing a model for adoption of cloud computing in education," International Journal of Information Management (36:2), pp 183-191.

70. Sahay, S., Monteiro, E., and Aanestad, M. 2009. "Configurable politics and asymmetric integration: Health e-infrastructures in India," Journal of the Association for Information Systems (10:5), p 4.

71. Saunders, M. N., Saunders, M., Lewis, P., and Thornhill, A. 2007. Research methods for business students, 4/e, (Pearson Education Iimited: Essex, England.

72. Schneider, S., and Sunyaev, A. 2014. "Determinant factors of cloud-sourcing decisions: reflecting on the IT outsourcing literature in the era of cloud computing," Journal of Information Technology (31:1), pp 1-31.

73. Scott, R. W. 2001. Institutions and organizations, (Thousand Oaks, Sage Publication: London.

74. Scott, W. R. 2008. "Approaching adulthood: the maturing of institutional theory," Theory and Society (37:5), pp 427-442.

75. Sidorova, A., Evangelopoulos, N., Valacich, J. S., and Ramakrishnan, T. 2008. "Uncovering the intellectual core of the information systems discipline," Mis Quarterly (31:3), pp 467-482.

76. Star, S. L., and Ruhleder, K. Year. "Steps towards an ecology of infrastructure: complex problems in design and access for large-scale collaborative systems," Proceedings of the 1994 ACM conference on Computer supported cooperative work, ACM1994, pp. 253-264.

77. Star, S. L., and Ruhleder, K. 1996. "Steps toward an ecology of infrastructure: Design and access for large information spaces," Information systems research (7:1), pp 111-134.

78. Sultan, N. 2014. "Making use of cloud computing for healthcare provision: Opportunities and challenges," International Journal of Information Management (34:2), pp 177-184.

79. Teo, H. H., Wei, K. K., and Benbasat, I. 2003. "Predicting Intention to Adopt Interorganizational Linkages: An Institutional Perspective," MIS Quarterly (27:1), pp 19-49.

80. Tilson, D., Lyytinen, K., and Sorensen, C. Year. "Desperately seeking the infrastructure in IS research: conceptualization of" digital convergence" as co-evolution of social and technical infrastructures," System Sciences (HICSS), 2010 43rd Hawaii International Conference on, IEEE2010a, pp. 1-10.

81. Tilson, D., Lyytinen, K., and Sørensen, C. 2010b. "Digital Infrastructures: The Missing IS Research Agenda 20th Anniversary Special Issue of Emerging Challenges," Information Systems Research (21:5), pp 748-759.

82. UNDP 2015. "Human Development Report 2015," United Nations Development Programme: New York, USA.

83. Ure, J., Procter, R., Lin, Y.-w., Hartswood, M., Anderson, S., Lloyd, S., Wardlaw, J., Gonzalez-Velez, H., and Ho, K. 2009. "The development of data infrastructures for ehealth: a socio-technical perspective," Journal of the Association for Information Systems (10:5), p 3.

84. Walsham, G. 1995. "Interpretive case studies in IS research: nature and method," European Journal of information systems (4:2), pp 74-81.

85. Wang, N., Liang, H., Jia, Y., Ge, S., Xue, Y., and Wang, Z. 2016. "Cloud computing research in the IS discipline: A citation/co-citation analysis," Decision Support Systems (86), pp 35-47.

86. Wilczek, M. 2018. "IT governance critical as cloud adoption soars to 96 percent in 2018," in CIO.

87. Yin, R. K. 2014. Case study research: Design and methods, (5th ed.) Sage Publications: Washington, USA.

88. Youseff, L., Butrico, M., and Da Silva, D. Year. "Toward a unified ontology of cloud computing," Grid Computing Environments Workshop, 2008. GCE'08, IEEE2008, pp. 1-10. 